\title{
Experimental and FEM Simulation Analysis of Lateral Extrusion Process on Bimetal Cross Fitting
}

\author{
Le Thai Hung ${ }^{1}$, Do Quang Long ${ }^{1}$, Le Trung Kien ${ }^{2}$, Vu Xuan Hung ${ }^{1}$, Pham Quang ${ }^{1}$, * \\ ${ }^{1}$ School of Material Science and Engineering, Hanoi University of Science and Technology, Hanoi, Vietnam \\ ${ }^{2}$ School of Mechanical Engineering, Hanoi University of Science and Technology, Hanoi, Vietnam
}

Email address:

hung.lethai@hust.edu.vn (Le T. Hung), dqlong66@gmail.com (Do Q. Long), kien.letrung@hust.edu.vn (Le T. Kien),

hungvx@gmail.com (Vu X. Hung), quang.pham@hust.edu.vn (P. Quang)

${ }^{*}$ Corresponding author

\section{To cite this article:}

Le Thai Hung, Do Quang Long, Le Trung Kien, Vu Xuan Hung, Pham Quang. Experimental and FEM Simulation Analysis of Lateral Extrusion Process on Bimetal Cross Fitting. Advances in Materials. Vol. 7, No. 3, 2018, pp. 67-72.

doi: $10.11648 /$ j.am.20180703.12

Received: June 17, 2018; Accepted: July 9, 2018; Published: August 15, 2018

\begin{abstract}
The purpose of this paper is to study combines the finite element method model and experimental on bimetal cross fitting by lateral extrusion process. Fabricating bimetallic cross fitting by lateral extrusion technique remains some difficulties like taking the product out of the die hardly, harming the die longevity since the high compressive force and friction effects. The Finite Element Method (FEM) results of bimetal cross fitting lateral extrusion process were obtained from ABAQUS software such as: Stress distribution, metal flow and influence of sleeve thickness. Numerical results were compared with the experimental results shown a good agreement. The bimetal cross fitting has been successfully fabricated by lateral extrusion process. The results showed a close agreement between the numerical simulation and experimental analysis of bimetal cross fitting.
\end{abstract}

Keywords: Bimetal, Cross Fitting, Lateral Extrusion, FEM

\section{Introduction}

Nowadays, extrusion technique [1] is commonly applied in industrial production, manufacturing component parts in industries of automobile, aircraft, means of transportation, machines, devices with typical products like bars, wires, solid or hollow tubes having cross sections from simple to complex. In addition, lateral extrusion generates shapes with flanges, collars or other geometric features (teeth, protrusions), whereby the die opening which gives the workpiece its shape remains unchanged during the entire forming process. [2-5]

Bimetal lateral extrusion is a metal forming operation which enables to manufacture products with optimal combination of desired properties. Initial billet consists of two different materials or two different alloys from the same material which are then deformed simultaneously. The most usual combination of two materials is the core-sleeve configuration. For example, core material may have high strength properties and sleeve material should own antifrictional properties. Other material properties can also be employed in bimetal operations such as magnetic, elastic expansion, electric conduction, etc.

M. Zadshakoyan et al $[6,7]$ studied the effect of die geometry and friction on the forming load and material flow in injection forging process as known as lateral extrusion process. The effect of friction in case I is greater than that in case II. Meanwhile, flange angle $(\alpha)$ increase by increasing $s / d$ ratio and better material flow can be obtained with the lower $s / d$ ratio. On the other hand, the results obtained shown that, if the initial work-piece diameter and the number of spline teeth increased, the value of forming load decreased and vice versa. The die angle affects to the forming load trivially, but the lower value of die angle is, the more difficult deformation performs, and fractures occur easily.

The three dimensional FE analyses has been used to investigate the effect of some important geometrical parameters such as initial billet diameter and height, gap height as well as process condition such as friction on the 
process. [8] Many studies about experimental investigation and 3-D analysis of lateral extrusion process on spur gear with involute profile. These studies almost focus on the effect of dimension parameters such as initial work-piece height and diameter, shape and thickness of product...on stroke and forming load. Thereby, investigating the effective stress and strain in each cases. $[9,10]$ The studies performed numerical and experimental analysis for two types of gear-like components with six teeth and encompasses preliminary numerical investigation of bimetallic cold extrusion of gearlike components. They focus type A with a straight radial tapered flank profile and type B with a straight tapered flank profileand investigating material flow of the billet which is combined of $\mathrm{Al}$ (core) and steel (sleeve) with variances of sleeve thickness. [11, 12]

At the end of the process, thickness of outer sleeve material was determined at four different sections. At sections A and B, thickness of outer sleeve increases during extrusion process compared to initial geometry, while sections $\mathrm{C}$ and $\mathrm{D}$ exhibit decreased thickness for all billet cases. The largest sleeve thickness for all combinations occurs at $\mathrm{B}$ section. Thickness is most critical at $\mathrm{C}$ section.

In this paper, the study about bimetallic materials is continued by numerical and experimental analysis of cross fitting lateral extrusion process.

\section{Simulaton Process and Exprimental}

\subsection{Simulation Process}

The numerical simulation performs three types of workpiece configuration with different thickness from $0.5,1.0$ and $2.0 \mathrm{~mm}$. Extrusion die was calculated based on principle of extrusion process and dimension of designed product.

Because the cross fitting is axisymmetric, so only $1 / 4$ of the model is used on FEM [13] simulation to get an accurate result and minimize analysis time. The work-pieces would be meshed of quadrilateral elements, suitable for die full-filled process.



Figure 1. Model of $1 / 4$ die and work-piece used in FEM simulation.
The selected materials for numerical simulation and experiment are pure lead (99.99\%) and AA6082 T6 aluminum alloy. Lead and aluminum are selected to perform numerical simulation, because they are deformed easily as same as steel in high temperature. Since, based on this researched results, the lateral extrusion process can be developed continuously with other materials in some cases.

Table 1. Material properties of work-pieces [14].

\begin{tabular}{llll}
\hline Material & $\begin{array}{l}\text { Young's } \\
\text { modulus (GPa) }\end{array}$ & Poisson's ratio & Density $\left(\mathbf{k g} / \mathbf{m}^{\mathbf{3}}\right)$ \\
\hline $\mathrm{Pb}(99.9 \%)$ & 16 & 0.44 & 11340 \\
$\mathrm{AA6082} \mathrm{T6}$ & 70 & 0.35 & 2700 \\
\hline
\end{tabular}

Compression testing is used to define the material model of $\mathrm{Pb}$. Testing sample have diameter $d=14.7 \mathrm{~mm}$, height $h=22.5 \mathrm{~mm}$.

Model material for Aluminum alloy uses this compression testing result. [15]

$$
\sigma=588 \times \varepsilon^{0.205}
$$

These material models of $\mathrm{Pb}(99.99 \%)$ and AA6082 T6 Aluminum alloy are used to simulate in Abaqus/CAE 6.13-1. [16] Numerical simulation boundary conditions were given in table below.

Table 2. Boundary consition for numerical simulation.

\begin{tabular}{ll}
\hline Parameters, characteristics & Value \\
\hline Work-piece temperature $\left({ }^{\circ} \mathrm{C}\right)$ & 25 \\
Friction, $f$ & 0.08 \\
Fixed and discrete rigid & \\
Stroke $(\mathrm{mm})$ & 30 \\
Sleeve thickness $(\mathrm{mm})$ & $0.5 ; 1 ; 2$ \\
\hline
\end{tabular}

\subsection{Expreimental Work}

As introduced in chapter 1, cross fitting is an important component in shaft driven. Nowadays, there are so many methods to manufacture cross fitting product, mostly by drawing technique. Lateral extrusion is one of working method used to fabricate cross fitting. Work-pieces used for experiment are $\mathrm{Al}-\mathrm{Pb} \quad(99.99 \%$ pure $)$ sleeve-core configuration.

The work-pieces are prepared by CNC Wire-Cut Machine, ensure that initial properties of them are not be changed. After cutting the work-pieces by designed dimension, they are polished and lubricated before processing

Table 3. Work-pieces dimensions.

\begin{tabular}{ll}
\hline Work-pieces & Dimension \\
\hline & $\mathrm{d}=70 \mathrm{~mm}$ \\
Sleeve $(\mathrm{Al})$ & $\mathrm{R}=14.7 \mathrm{~mm}$ \\
& $\mathrm{r}=10.7 \mathrm{~mm}$ \\
Core $(\mathrm{Pb})$ & $\mathrm{d}=70 \mathrm{~mm}$ \\
& $\mathrm{R}=10.7 \mathrm{~mm}$ \\
\hline
\end{tabular}




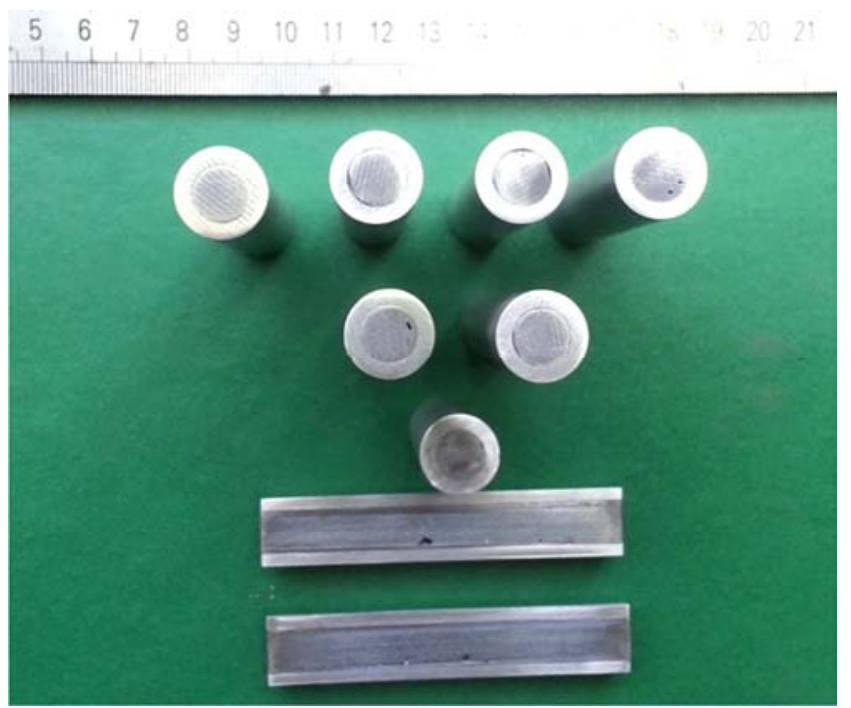

Figure 2. Bimetallic work-piece Al-Pb sleeve-core configuration.

\subsection{Dies Preparation}

Lower and upper die is created by the dimension is calculated and designed by Solid-works.

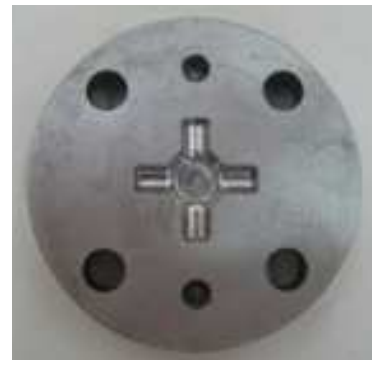

(a)

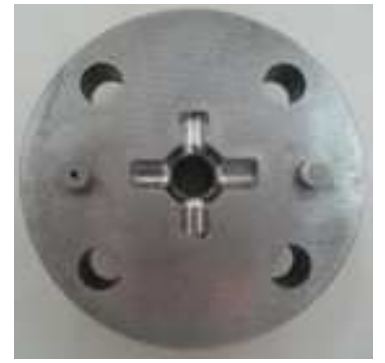

(b)
Figure 3. Lower die (a) and upper die (b) used for experiment.

The dies are made of SKD-16 steel as shown in Figure 3. Using glass-paper to clear the dies and lubricate by silicone spray lubricant Punch is made of SKD-11 steel. It is cleared, but is not lubricated for the experiment to prevent the reverse flow of metal.

The pressing machine used for experiment is MTS 809.10 A/T. Hydraulic power with maximum compressive force up to 10 tons is used in this machine.

\section{Results and Discusions}

The lateral extrusion process for cross fitting can be divided in to five stages (Figure 4). Stage 1 (AB) is a free stamping, from (B) metal flows into the die inside. Until (C), metal start to fill branches of cross fitting, begin the period of stable and continuous metal flow (CD). In this stage, compressive force almost do not change. At (D), metal begin to touch the die-wall and the force begin increasing. Stage (DE) is die full-filled period. From (E), metal fill fully the branches of the die, and also from here, the sleeve of workpiece begin to thin and tend to be fractured. According to the simulation result, the lateral extrusion process from onedirection is not available for bimetallic products. Twodirection pressing are recommended.

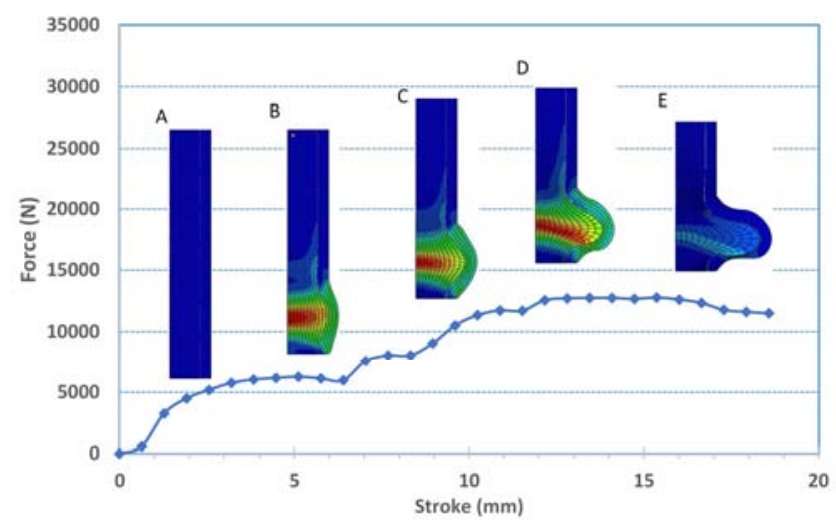

Figure 4. Force-Stroke diagram and equivalent plastic strain of work-pieces for simulation with $v=1 \mathrm{~mm} / \mathrm{s}, f=0.08$.

\subsection{Analysis of Stress in Simulation}

Stress is a characteristic parameter for energy process development in compressive technique. In deformation areas that have large strain impedance will occur high stress field. Stress field distribution on work-pieces has shown step by step in these Figure 5.

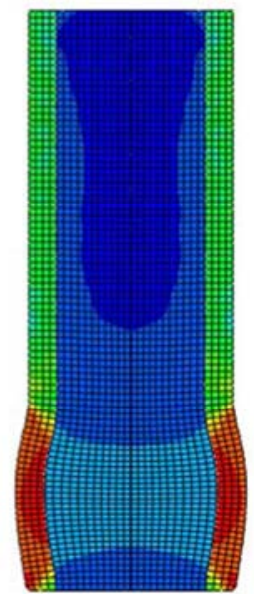

(a)
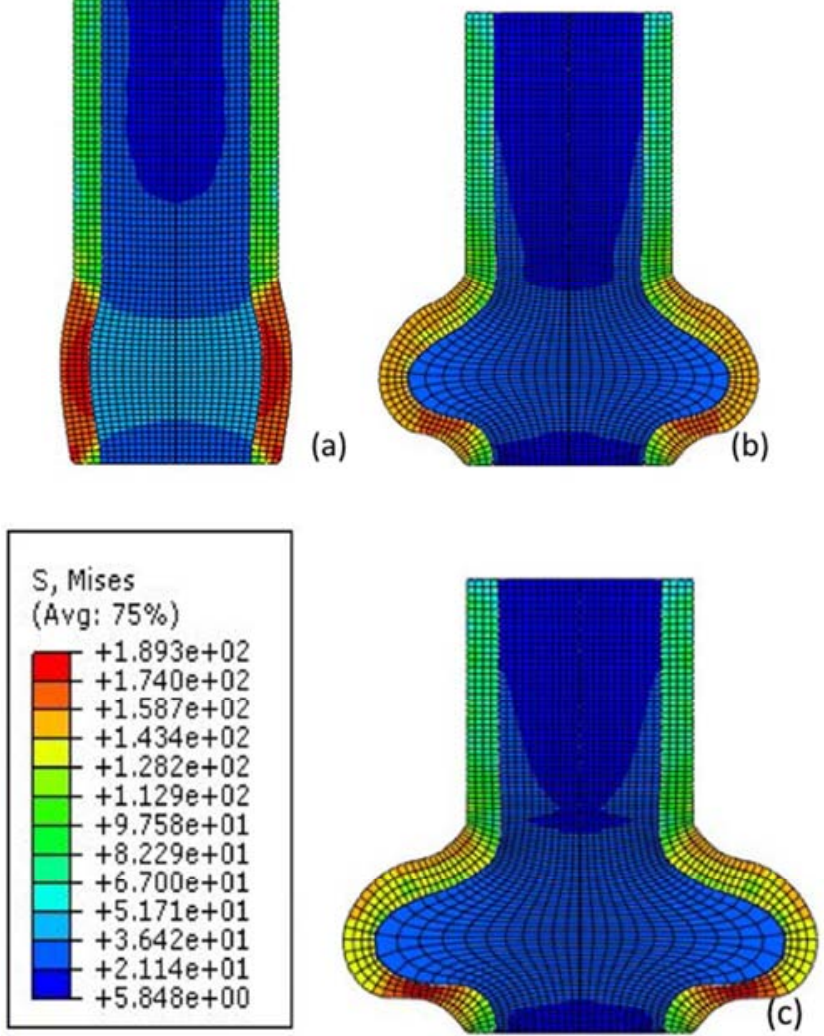

Figure 5. Stress field of work-piece step by step. 
During lateral extrusion process, stress concentrated mostly on interface areas and tends to focus on center area of product. As shown in the figure, sleeve material areas take the highest stress, especially in the bottom of the product, where the work-pieces initially touch the die wall. Since, the magnitude of compressive force increase more and more until the end of the process.

\subsection{Metal Flow in Deformation Process}

Deformation process in lateral extrusion method are fairly complex. The metal flow change dependently on applied force direction. In this case, the metal direction of metal flow are perpendicular to the punch direction.

The Figure 6 show the velocity vector of metal flow during deformation process step by step. Easily see that, the metal flow run uniformly and stably, forming metal fibers.

Based on numerical simulation, we can totally study the metal flow in lateral extrusion technique and other metal working methods, in order to making comparison and judgment about compressive force and metal flow in each cases.


Figure 6. Metal flow in lateral extrusion process by simulation.

\subsection{Effect of Sleeve Thickness}

For bimetallic extrusion process, the sleeve thickness is specially considered. Because it affects intensively to the working process, and also the products quality. Some values of sleeve thickness were investigated: $0.5 \mathrm{~mm}, 1 \mathrm{~mm}$ and 2 mm (Figure 7).

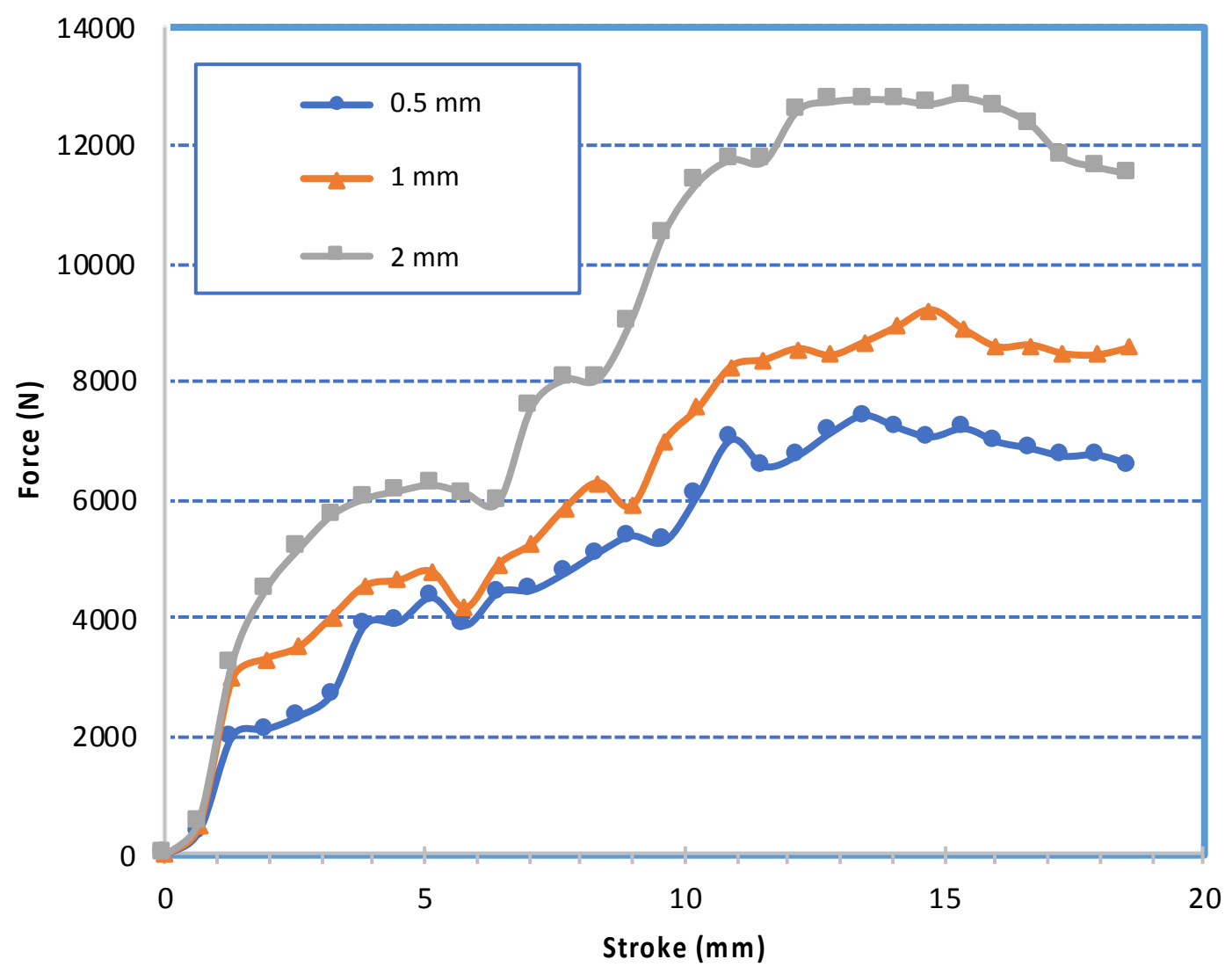

Figure 7. Effect of sleeve thickness on compressive force.

According to the simulation results above, the larger sleeve thickness requires higher compressive force.

This factor do not only affect the compressive force, but also affects the shape and mechanical properties of products.

From Figure 8 and table 3, the sleeve thicknesses affect fairly to the uniformity of the product. As shown in table 3, region $\mathrm{A}$ and $\mathrm{C}$ express nearly homogeneous distribution of metal. However, in region $B$, the sleeve thickness is decreased significantly. This can greatly affect not only to the shape, but also to the mechanical properties of the product. Since, to minimize the reducing of metal amount in the sleeve, it might be designed with thicker dimension in acceptable limit. 


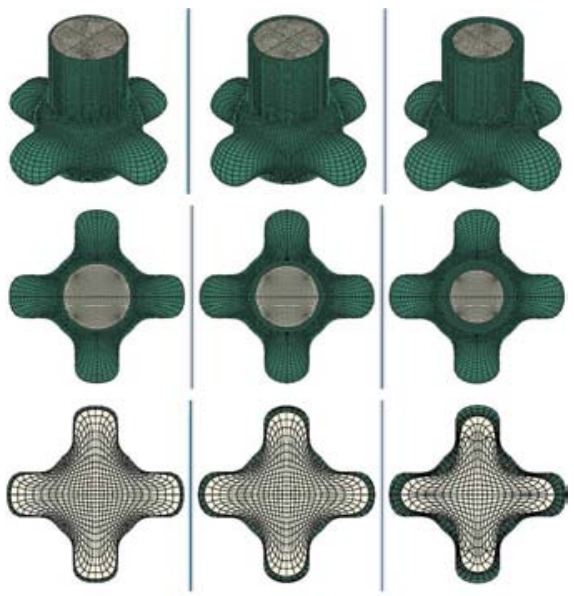

Figure 8. Sleeve thickness variations.

The simulation results show us the distribution of stress field on surface and cross-sectional area of cross fitting product. Defined the position of high stress concentration and easily fracture areas.

Metal flow in lateral extrusion process is also investigated, therefore, lateral extrusion method can manufacture products with high mechanical properties, because of uniform metal flow and metal fibers forming.

Based on the theory, technical parameters like friction coefficient, velocity, work-piece dimension and sleeve thickness, affect the stroke of punch, compressive force in the process.

Table 3. Thickness distribution of sleeve material.

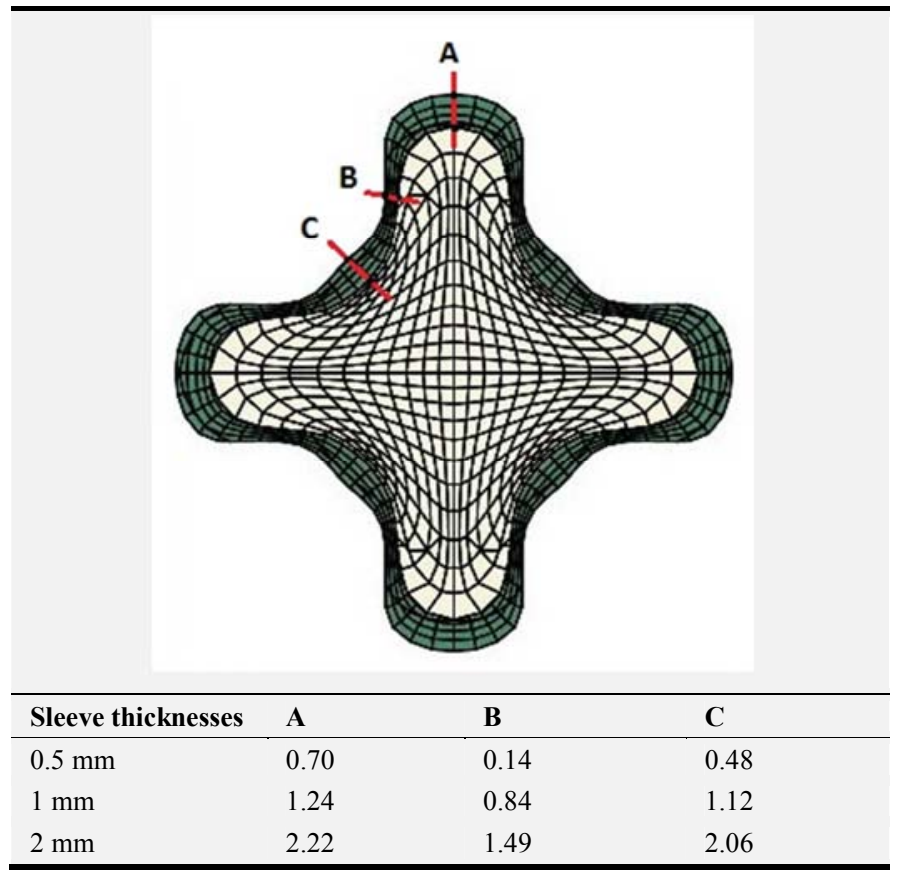

\subsection{Experiment Results}

From the experimental result, easily see that, the product is qualifed the requirement about shape, dimension. But the sleeve material is fractured because of the symmetric shape of cross fitting and one-direction force.

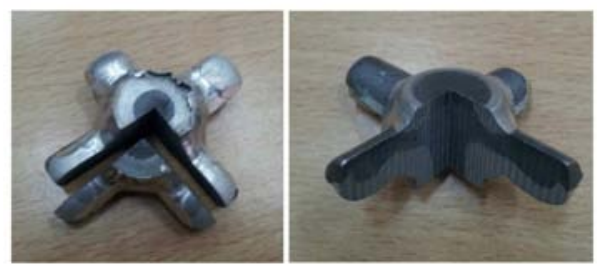

Figure 9. Experiment product.
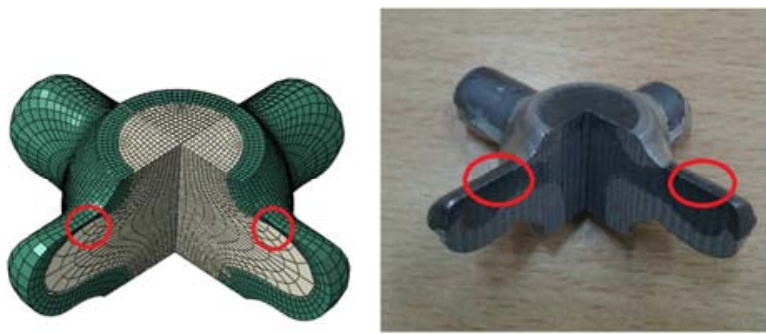

Figure 10. Simulation (a) and experiment (b) results.

The experiment results show that, by one-direction working, the bimetallic cross fitting product cannot be manufactured successfully. As shown in the experimental Figures 9 and 10, the sleeve work-piece is fractured at the bottom region, because the compressive force applied by one-direction.

According to the experiment result, the obtained product is qualified the requirement about shape and dimension. Unfortunately, the sleeve material tends to be fractured because of symmetric particularity of the cross fitting. Hence, lateral extrusion process by one-direction force is totally not suitable for bimetallic product manufacture. After performing numerical simulation and experimental analysis, twodirection pressing is considered for manufacturing bimetallic products.

\section{Conclusion}

Fabricating bimetallic cross fitting by lateral extrusion technique remains some difficulties like taking the product out of the die hardly, harming the die longevity since the high compressive force and friction effects. However, lateral extrusion is still one of the most valuable methods to create products required high strength. Furthermore, lateral extrusion technique has some advantages than other traditional methods like saving materials, minimizing postprocessor, high productivity; good surface finished and high accuracy of dimension. Specially, comparing to traditional methods, lateral extrusion technique creates products with high mechanical properties because of uniform and continuous metal flow.

Based on numerical analysis such as stress distribution, metal flow and the effect of friction, sleeve thickness on bimetal cross fitting forming process, suitable parameters were chosen to perform experiment.

The bimetal cross fitting has been successfully fabricated by lateral extrusion process. The results showed a close agreement between the numerical simulation and 
experimental analysis of bimetal cross fitting.

\section{References}

[1] T. Altan, "Lateral extrusion Solid forming, Metal Forming Handbook", Schuler (c) Springer-Verlag Berlin Heidelberg (1998).

[2] U. C. Paltasingh, S. K. Sahoo, P. Dash, K. C. Nayak,"Simulation and experimental studies for lateral extrusion of square and pentagonal head from round shaft", International Journal of Research in Engineering and Technology. (2013) pp. 2319-1163.

[3] M. Zadshakoyan, H. Jafarzadeh, E. A. Sobbouhi, "Injection forging of splines using numerical and experimental study", International Journal of Aerospace and Mechanical Engineering 4, (2010) pp. 179-184.

[4] H. Jafarzadeh, M. Zadshakoyan, "Numerical and experimental studies of splines produced by injection forging process", Materials and Manufacturing Processes 26 (5), (2011) pp. 703-712.

[5] M. Zadshakoyan, E. A. Sobbouhi, H. Jafarzadeh, "Investigation of precision forging process of spur gears: Numerical analysis and experiments", Advanced Materials Research 341, (2012) pp. 265-270.

[6] M. Zadshakoyan, H. Jafarzadeh, E. Abdi Sobbouhi, "Injection Forging of Splines Using Numerical and Experimental Study", Engineering and Technology International Journal of Industrial and Manufacturing Engineering Vol:3, No:4, (2009) pp. 422-427.

[7] M. Zadshakoyan and H. Jafarzadeh, "Numerical Study of the Die Geometry and Friction Effect on the Forming Load and Material Flow in Injection Forging Process". Journal of Applied Sciences, 9 (2009) pp. 2174-2179.
[8] H. Jafarzadeh, G. Faraji and A. F. Dizaji, "Analysis of lateral extrusion of gear-like form parts," Journal of Mechanical Science and Technology 26 (2012) pp. 3243-3252

[9] U. C. Paltasingh, S. K. Sahoo, P. R. Das, K. C. Nayak, S. Potnuru, "Lateral Extrusion of Spur gears with Involute Profile: Finite Element Analysis and Experimental Investigation", IOSR Journal of Engineering (IOSRJEN), Vol. 3, Issue 7 (2013) pp. 20-30.

[10] U. C Paltasingh, S. K. Sahoo, P. R. Dash, K. C. Nayak, S. Potnuru, "FEM Analysis And Experimental Investigation For Lateral Extrusion Of Hexagonal Head", International Journal of Engineering Research and Applications (IJERA), Vol. 3, Issue 4, (2013), pp. 1265-1271.

[11] M. Plančak, M. Rosochowska, P. Skakun, "Radial extrusion of gear like components - numerical analysis and experiment", Technical Gazette 20, 5(2013), pp. 891-896.

[12] I. Kačmarčik, M. Plančak, D. Vilotić, M. Tolnai, D. Movrin, A. Ivanišević, "Numerical analysis of bi-metallic extrusion of gear-like components", The 6th PSU- UNS International Conference on Engineering and Technology, ICET2013 T. 101. 3, (2013) pp. 1-4.

[13] O. C. Zienkiewicz and R. L. Taylor, "The Finite Element Method (Vol. 2: Solid Mechanics)," Published by Butterworth-Heinemenn (2000).

[14] E. A. Brandes, "Smithells metals reference book", Butterworths, (1988).

[15] A. S. Scari, B. C. Pockszevnicki, J. L. Junior and P. A. A. M. Junior, "Stress-Strain Compression of AA6082-T6 Aluminum Alloy at Room Temperature", Journal of Structures Volume (2014), Article ID 387680, 7 pages.

[16] Abaqus 6. 13: Abaqus/CAE User"s Manual. 